\title{
Vulnerability Assessment of Maize Yield Affected by Precipitation Fluctuations: A Northeastern United States Case Study
}

\author{
Peng Su ${ }^{1}$, Shiqi $\mathrm{Li}^{2}$, Jing'ai Wang ${ }^{1,3, *}$ and Fenggui Liu ${ }^{1,4}$ \\ 1 School of Geographical Science, Qinghai Normal University, Xining 810008, China; \\ 201947331031@stu.qhnu.edu.cn (P.S.); liufenggui@igsnrr.ac.cn (F.L.) \\ 2 Spatial Science Institute, University of Southern California, Los Angeles, CA 90089, USA; shiqi@usc.edu \\ 3 Faculty of Geographical Science, Beijing Normal University, Beijing 100875, China \\ 4 Academy of Plateau Science and Sustainability, Xining 810008, China \\ * Correspondence: jwang@bnu.edu.cn
}

Citation: Su, P.; Li, S.; Wang, J.; Liu, F. Vulnerability Assessment of Maize Yield Affected by Precipitation Fluctuations: A Northeastern United States Case Study. Land 2021, 10, 1190 https://doi.org/10.3390/land10111190

Academic Editors: Baojie He, Ayyoob Sharifi, Chi Feng and Jun Yang

Received: 24 September 2021 Accepted: 1 November 2021 Published: 5 November 2021

Publisher's Note: MDPI stays neutral with regard to jurisdictional claims in published maps and institutional affiliations.

Copyright: () 2021 by the authors. Licensee MDPI, Basel, Switzerland. This article is an open access article distributed under the terms and conditions of the Creative Commons Attribution (CC BY) license (https:// creativecommons.org/licenses/by/ $4.0 /)$.

\begin{abstract}
Crop yields are threatened by global climate change. Maize has high water requirements, and precipitation fluctuations can impact its yield. In this study, we used the Environmental Policy Integrated Climate (EPIC) model to simulate maize yields in eight northeastern U.S. states. We used precipitation fluctuations and the coefficient of variation (CV) of yield as indicators to construct a vulnerability curve for the $\mathrm{CV}$ of yield and precipitation fluctuations. We then evaluated the vulnerability of maize yields under precipitation fluctuations in the region. We obtained the following results: (1) the fitted vulnerability curves were classified into three categories (positive slope, negative slope, and insignificant fit), of which the first category accounted for about $92.7 \%$, indicating that the CV of maize yield was positively correlated with precipitation fluctuations in most parts of the study area; and (2) the CV of maize yield under 11 precipitation fluctuation scenarios was mapped to express the CV at the spatial level, and the maize yield in Connecticut and Maryland proved to be the most sensitive to precipitation fluctuations. This study provided a theoretical and experimental basis for the prevention of maize yield risk under fluctuating precipitation conditions.
\end{abstract}

Keywords: precipitation fluctuation; vulnerability curve; maize yield; EPIC model; risk assessment

\section{Introduction}

High and stable crop yields are the key to food security and sustainable development. Since the beginning of industrialization, global surface temperatures have increased in the context of climate change, which has led to an increase in terrestrial droughts and greater fluctuations in precipitation, thus adversely affecting food production [1]. Therefore, researchers are increasingly turning their attention to studying the relationships between climate change and crop yield, assessing crop vulnerability under climate change conditions, and preventing and mitigating the effects of hazards caused by climate change on crop yield [2-4]. Vulnerability studies are useful to analyze the impact of precipitation fluctuations on maize yields, so that appropriate planting adjustments can be made to stabilize crop yields.

Disaster risk assessment in a broad sense is a holistic risk assessment of a hazard system based on separate assessments of the hazard-bearing body, the hazard intensity, and the environment [5]. Vulnerability is an important component of crop risk assessment, where vulnerability is defined as the response of the hazard-bearing body to damage by the hazard [6,7]. Vulnerability is used to measure the degree of damage caused to a crop [8]. Vulnerability curves are a way to visually represent losses at each level of hazard causation. The representation of the vulnerability curve consists of two components: the hazard and the hazard-bearing body. Regarding the hazard, Shi et al. [9] divided climate change into 
three parts: trends, fluctuations, and extreme events. At present, most studies on vulnerability have focused on extreme events [10-13], and fewer studies have been conducted on trends [14,15] and especially on fluctuations [7]. For example, Zhong et al. [16] assessed the drought risk in the Yun-Gui-Guang region of China by using vulnerability curves, and they calculated agricultural losses under different drought levels; Li et al. [17] studied maize yield loss caused by excessive rainfall in the United States, highlighting the need to study the impact of excessive rainfall on crop yield; Jayanthi et al. [18] obtained drought vulnerability curves for maize by fitting the relative evapotranspiration deficit and relative maize yield loss. It is thus clear that current vulnerability studies focus on direct crop losses, while equally important studies on the yield stability of crops and other responses to climate change are lacking.

Precipitation fluctuations are fluctuations relative to long-term average precipitations [19]. Unlike direct damage to crop yield by extreme precipitation events, precipitation fluctuations can impact on the mean crop yield and its stability at multiple spatial scales [20,21]. Lobell and Burke [22] found that changes in the standard deviation of inter-annual precipitation in the growing season can lead to yield variations of South Asian cereals of up to $8 \%$; Hamilton et al. [23] found that seasonal precipitation variations were positively correlated with changes in forage yield in south-eastern Wyoming, with the yield variation in forage reaching $25.5 \%$ under a scenario of a $50 \%$ increase in standard deviation of precipitation. All the above studies demonstrated that increased precipitation fluctuations led to increased variability in crop yields and increased crop yield instability; however, these studies did not implement this relationship as a functional relationship and lacked spatialized expressions. Thus, further relationship characterization is still needed.

To construct vulnerability curves using crop yields and climate characteristics, a crop model is required to simulate the relationship between crop growth and yield [24]. Crop models are based on systems science, with temperature, moisture, light, and soil as environmental driving variables, and they use computer technology and mathematical and physical methods to simulate the relationship between crop growth and yield $[25,26]$. The Environmental Policy Integrated Climate (EPIC) model is one of the models that has been widely used for crop vulnerability studies [27-32]. Jia et al. [33] used the EPIC model to simulate maize yield under different moisture stresses in the Huang-Huai-Hai plain in northern China, resulting in a drought vulnerability curve for the summer maize region, and further mapped the yield loss distribution under different hazard intensities. Wang et al. [34] used the EPIC model to calculate the rate of wheat yield loss of two typical wheat varieties in China under varying water drought stresses, and evaluated the drought vulnerability of wheat in China. Guo et al. [35] used the EPIC model with several irrigation scenarios to construct several global three-dimensional maize drought vulnerability surfaces.

In summary, the use of vulnerability curves to study the vulnerability of crop yield can describe crop losses for different degrees of hazard intensities. In this study, we simulated and plotted maize yield vulnerability curves under different precipitation fluctuation scenarios based on meteorological and crop statistics for eight northeastern U.S. states from 1981 to 2015, to investigate multi-year precipitation fluctuations and maize yield vulnerability. The objectives of this paper were as follows: (1) fit the vulnerability curves between different precipitation fluctuation scenarios and the $\mathrm{CV}$ of maize yield, to quantify the functional relationship between maize yield stability and precipitation fluctuation; and (2) spatialize the vulnerability curve characteristics to characterize the degree of vulnerability in different regions. Thus, mitigation measures can be formulated to reduce crop yield instability caused by precipitation fluctuations and to ensure the stability of grain production. 


\section{Materials and Methods}

\subsection{Basic Idea and Research Framework}

This study focused on the construction of vulnerability curves for maize under precipitation fluctuation scenarios, and analyzed the $\mathrm{CV}$ of maize yields under these different scenarios. The framework of this study was as follows: (1) set 11 precipitation fluctuation scenarios and invert 11 precipitation datasets according to the fluctuation scenario; (2) use the EPIC model to calculate maize yield under each fluctuation scenario; and (3) calculate the $\mathrm{CV}$ based on simulated maize yields. The results of the EPIC model were also validated using actual maize yield data for the 5-year period from 2000 to 2004, to prove the usability of the EPIC model simulation results.

The overall research framework for the study is shown in Figure 1.
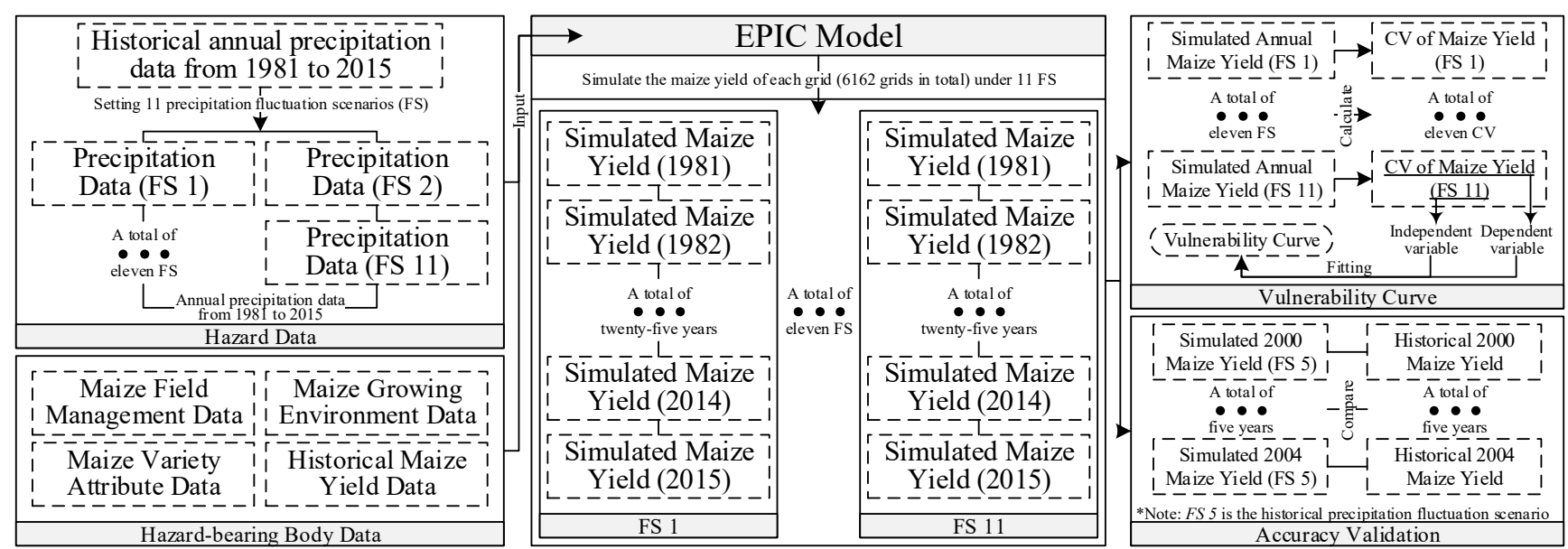

Figure 1. Research framework for the study.

\subsection{Case Study}

As the world's top exporter of agricultural products, the United States also ranks first in the world in maize production [36]. The northeastern United States region belongs to the mixed agricultural belt, its agriculture being dominated by dairy livestock farming [37]. Silage corn is also grown in large quantities locally as livestock feed [38]. Maize is one of the three major food crops in the world [39], and the yield instability of this crop can have a large economic impact on the world and even threaten world food security [40]. The sensitivity of maize to water scarcity is increasing under a changing climate; thus, it is important to study the vulnerability of maize to precipitation fluctuations.

The study area consisted of eight states in the northeastern United States with a total area of about $399,035 \mathrm{~km}^{2}$ and a land area of about 362,135 km², including New York, Connecticut, Pennsylvania, New Jersey, Delaware, Maryland, West Virginia, and Virginia (Figure 2). The topography of the region has a relative elevation difference of about $1700 \mathrm{~m}$, with many plateaus and mountains, and the Appalachian Mountains running through it. The northern part of the region has a humid continental climate, while the southern part has a humid subtropical climate. The region encompasses the political and economic centers of the United States, and has a large population, accounting for $22 \%$ of the total population of the United States. 


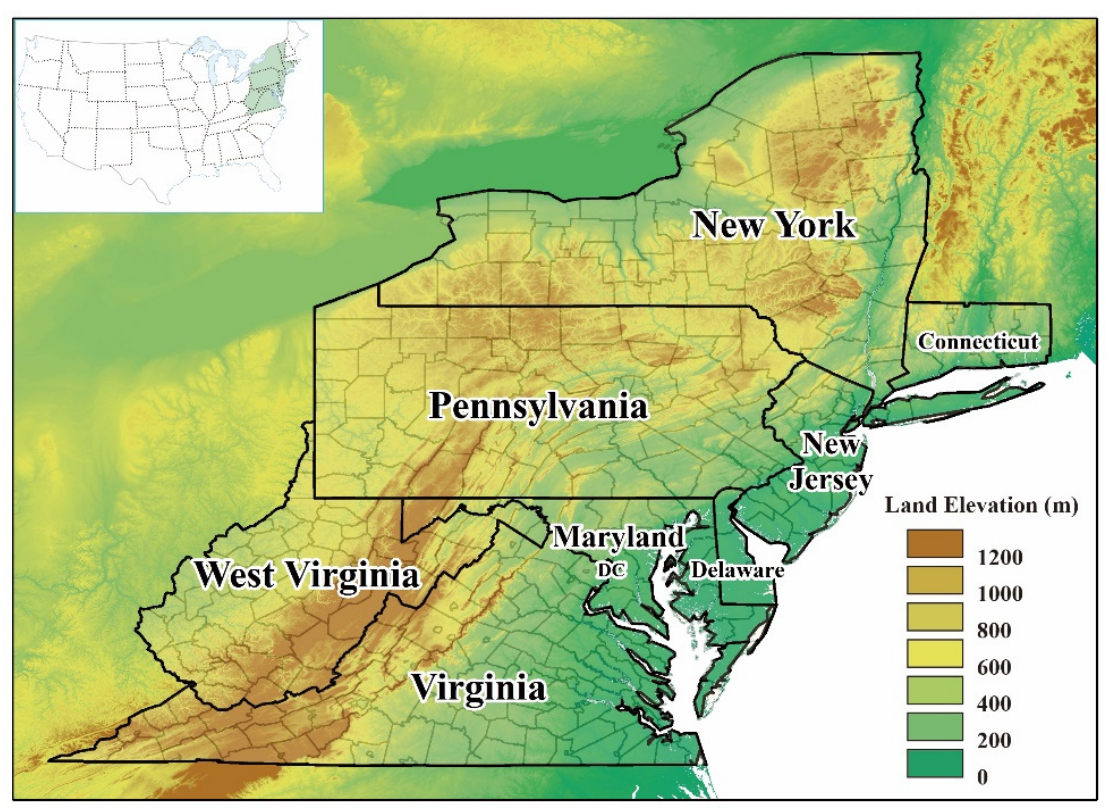

Figure 2. Location map of study area with elevation.

\subsection{Data Collection}

The data used in this study were divided into three categories (Table 1). The first category was natural environmental data. It included elevation data from the United States Geological Survey (USGS) and slope data calculated from elevation; precipitation, temperature, and wind speed data generated under the GEM2-ES climate model; fertilizer application data from the Socioeconomic Data and Applications Centre (SEDAC); and Soil data from the International Soil Reference and Information Centre (ISRIC). These data were input into the EPIC model. The second category was crop statistics data, including county-by-county maize production and state-by-state growing season information from the United States Department of Agriculture (USDA). The third category was geographic information data. It included state and county boundary vector data and land use data. The boundary data were obtained from the USDA. Land use data used to map farmland came from the Food and Agriculture Organization (FOA).

Table 1. Database.

\begin{tabular}{|c|c|c|c|c|}
\hline Data Name & Spatial Resolution & Temporal Resolution & Unit & Source \\
\hline Elevation & $90 \mathrm{~m} \times 90 \mathrm{~m}$ & 2007 & $\mathrm{~m}$ & $\begin{array}{c}\text { USGS-EarthExplorer } \\
\text { https:/ / earthexplorer.usgs.gov / } \\
\text { (accessed on } 31 \text { October 2021) }\end{array}$ \\
\hline Slope & $90 \mathrm{~m} \times 90 \mathrm{~m}$ & 2007 & $\mathrm{~m}$ & Calculated by ArcGIS \\
\hline Land Use & $5^{\prime} \times 5^{\prime}$ & 2015 & / & $\begin{array}{c}\text { EarthStat, FOA } \\
\text { http://www.earthstat.org/ } \\
\text { (accessed on 31 October 2021) } \\
\text { http://www.fao.org/faostat/en/ } \\
\text { (accessed on 31 October 2021) }\end{array}$ \\
\hline $\begin{array}{l}\text { Historical Crop } \\
\text { Yield }\end{array}$ & County unit & 2000-2004 & t/ha & $\begin{array}{c}\text { USDA/NASS QuickStats } \\
\text { https:/ / www.nass.usda.gov/Quick_Stats / } \\
\text { (accessed on 31 October 2021) }\end{array}$ \\
\hline Fertilization & $0.5^{\circ} \times 0.5^{\circ}$ & 2010 & $\mathrm{~kg} / \mathrm{ha}$ & $\begin{array}{c}\text { SEDAC } \\
\text { https: / / sedac.ciesin.columbia.edu/ } \\
\text { (accessed on 31 October 2021) }\end{array}$ \\
\hline
\end{tabular}


Table 1. Cont.

\begin{tabular}{|c|c|c|c|c|}
\hline Data Name & Spatial Resolution & Temporal Resolution & Unit & Source \\
\hline Irrigation & County unit & 2015 & $10^{6} / \mathrm{m}^{3}$ & $\begin{array}{c}\text { USGS } \\
\text { https:/ / pubs.er.usgs.gov/publication/ cir1441 } \\
\text { (accessed on 31 October 2021) }\end{array}$ \\
\hline $\begin{array}{l}\text { Crop Growth } \\
\text { Period }\end{array}$ & State unit & / & / & $\begin{array}{c}\text { USDA/NASS QuickStats } \\
\text { https:/ / www.nass.usda.gov/Quick_Stats / } \\
\text { (accessed on 31 October 2021) }\end{array}$ \\
\hline Soil Type & $5^{\prime} \times 5^{\prime}$ & 2012 & / & $\begin{array}{c}\text { ISRIC-WISE } \\
\text { https:// www.isimip.org/gettingstarted/ } \\
\text { input-data-bias-correction/ } \\
\text { (accessed on 31 October 2021) }\end{array}$ \\
\hline Precipitation & $0.5^{\circ} \times 0.5^{\circ}$ & 1971-2015 & $\mathrm{mm}$ & $\begin{array}{c}\text { ISIMIP-hadGEM2-ES } \\
\text { https:/ / www.isimip.org/gettingstarted/ } \\
\text { input-data-bias-correction/ } \\
\text { (accessed on 31 October 2021) }\end{array}$ \\
\hline Temperature & $0.5^{\circ} \times 0.5^{\circ}$ & 1971-2015 & ${ }^{\circ} \mathrm{C}$ & $\begin{array}{c}\text { ISIMIP-hadGEM2-ES } \\
\text { https:/ / www.isimip.org/gettingstarted/ } \\
\text { input-data-bias-correction/ } \\
\text { (accessed on 31 October 2021) }\end{array}$ \\
\hline Wind Speed & $0.5^{\circ} \times 0.5^{\circ}$ & 1971-2015 & $\mathrm{m} / \mathrm{s}$ & $\begin{array}{c}\text { ISIMIP-hadGEM2-ES } \\
\text { https:/ / www.isimip.org/gettingstarted/ } \\
\text { input-data-bias-correction/ } \\
\text { (accessed on 31 October 2021) }\end{array}$ \\
\hline $\begin{array}{l}\text { Administrative } \\
\text { Boundary }\end{array}$ & County unit & 2015 & / & $\begin{array}{c}\text { USDA/NASS QuickStats } \\
\text { https:/ / www.nass.usda.gov/Quick_Stats/ } \\
\text { (accessed on } 31 \text { October 2021) }\end{array}$ \\
\hline
\end{tabular}

\subsection{Methods}

\subsubsection{Calculation of Precipitation Fluctuations}

Precipitation fluctuation can be defined as the interannual variation in precipitation after detrend. It can also be understood as the upward and downward variation of precipitation relative to the long-term average condition. Therefore, the standard deviation is generally used to characterize the fluctuation in precipitation. In this study, 11 precipitation fluctuation scenarios were pre-defined. Different scenarios were applied with 11 different precipitation fluctuation multiplicities (FLU): $20 \%, 40 \%, 60 \%$, and $80 \%$ decreases in standard deviation; $0 \%, 20 \%, 40 \%, 60 \%, 80 \%, 100 \%$, and $120 \%$ increases in standard deviation. According to a certain precipitation fluctuation scenario, this paper calculated the amount of precipitation corresponding to the scenario, as shown in Equation (1).

$$
P(q j)=P+\operatorname{Std}(P) \cdot \mathrm{FLU}
$$

where $P(q j)$ refers to the annual precipitation under a certain precipitation fluctuation; $P$ refers to the value of annual precipitation from 1981 to 2015; Std $(P)$ refers to the standard deviation of precipitation from 1981 to 2015; and FLU refers to the precipitation fluctuation multiplier with values from $-80 \%$ to $120 \%$ in steps of $20 \%$.

After calculating the annual precipitation for each year from 1981 to 2015 under the 11 precipitation fluctuation scenarios, this paper distributed the annual precipitation in proportion to each day and obtained the daily precipitation data for the 11 fluctuation scenarios. The daily precipitation data were used in the simulation of the EPIC model with daily steps. The detailed daily precipitation distribution process is shown in Equation (2).

$$
P_{i, y}(q j d)=P(q j) \cdot \frac{P_{i, y}}{P_{y}}
$$


where $i$ refers to the $i$ th day of the year; $y$ refers to the year (from 1981 to 2015); $P_{i, y}(q j d)$ refers to the daily precipitation under a certain precipitation fluctuation; $P(q j)$ refers to the annual precipitation under a certain precipitation fluctuation; $P_{i, y}$ refers to the value of daily precipitation on the $i$ th day of the $y$ year; $P_{y}$ refers to the value of annual precipitation of the $y$ year.

\subsubsection{Calculation of CV of Crop Yield}

In calculating the crop yield variability, the trend of its yield increasing caused by technological progress should be excluded. Thus, the stability of crop yields can be expressed as the coefficient of variation (CV) of the base state multi-year yield. This paper referred to Zhao et al. [41] using the adjusted coefficient of variation to monitor the global trend of grain yield stability. The CV of crop yield is calculated by dividing the standard deviation of crop yield over many years by its arithmetic mean, as shown in Equation (3). A larger CV of crop yield indicates poorer yield stability.

$$
\mathrm{CV}=\frac{\sigma}{\mu} \times 100 \%
$$

where CV refers to the coefficient of variation of maize yield, $\sigma$ refers to the standard deviation of simulated maize yield in the study area for 35 years (from 1981 to 2015), and $\mu$ is the arithmetic mean of simulated maize yield in the study area for 35 years.

In this paper, the vulnerability curve was fitted using the precipitation fluctuation multiplier as the independent variable and the $\mathrm{CV}$ value of simulated maize yield as the dependent variable. The fitting equation was as follows (Equation (4)).

$$
\mathrm{CV}=\mathrm{k} \times \mathrm{FLU}+\mathrm{b}
$$

where the independent and dependent variables refer to the precipitation fluctuation multiplier (FLU) and the coefficient of variation (CV) of maize yield, respectively; $k$ and $b$ are parameters.

\subsubsection{Maize Yield Simulation by Using the EPIC Model}

The EPIC model is composed of numerous components, including an erosion module, hydrology module, weather generator, crop growth module, and crop management module. A general plant growth model with crop-specific parameters is used to simulate the growth of variety crops, such as rice, wheat, and maize [32]. We used the EPIC0509 version in this paper, which can be downloaded from http:/ / epicapex.tamu.edu/epic/ (accessed on 31 October 2021).

Based on the data input requirements of the EPIC model [42], this paper divided the data in the study area into four categories: (1) maize growing environment data, including the meteorological data (highest temperature, lowest temperature, and precipitation data), terrain data (elevation and slope), and soil property data; (2) maize field management data, including fertilization data and irrigation data; (3) maize variety attribute data, including maize growth period; (4) historical maize yield data. After considering the resolution of the data used, the study area was divided into grids of $5^{\prime} \times 5^{\prime}$ (about $10 \mathrm{~km}$ ). In this paper, the grids with a maize planting percentage greater than 0 were defined as maize planting areas, and 6162 grids were obtained by grid creation and screening by using ArcGIS. Each grid was used as an independent EPIC model run cell, the EPIC model input data for that grid were obtained by spatial overlay calculation in ArcGIS, and the batch EPIC model run on each grid was realized by MATLAB programming. In order to obtain crop yield variation under different precipitation fluctuation scenarios, this study set-up a simulation environment with no temperature stress, aerated stress, and nutrient stress (nitrogen stress, phosphorus stress, and potassium stress), and then simulated the impact of water stress on crop yield. 
In the specific application of the EPIC model, the parameters should be adjusted according to the actual local conditions [43]. The model in this paper was adjusted with statistical yield data for five years during 2000-2004, modified the maize variety attribute data to reduce the difference between simulated and statistical yields, and iterated five times to obtain the final maize variety attribute data. These data were used as the final maize variety attributes input data to obtain the simulated yield results. The process is as Figure 3.

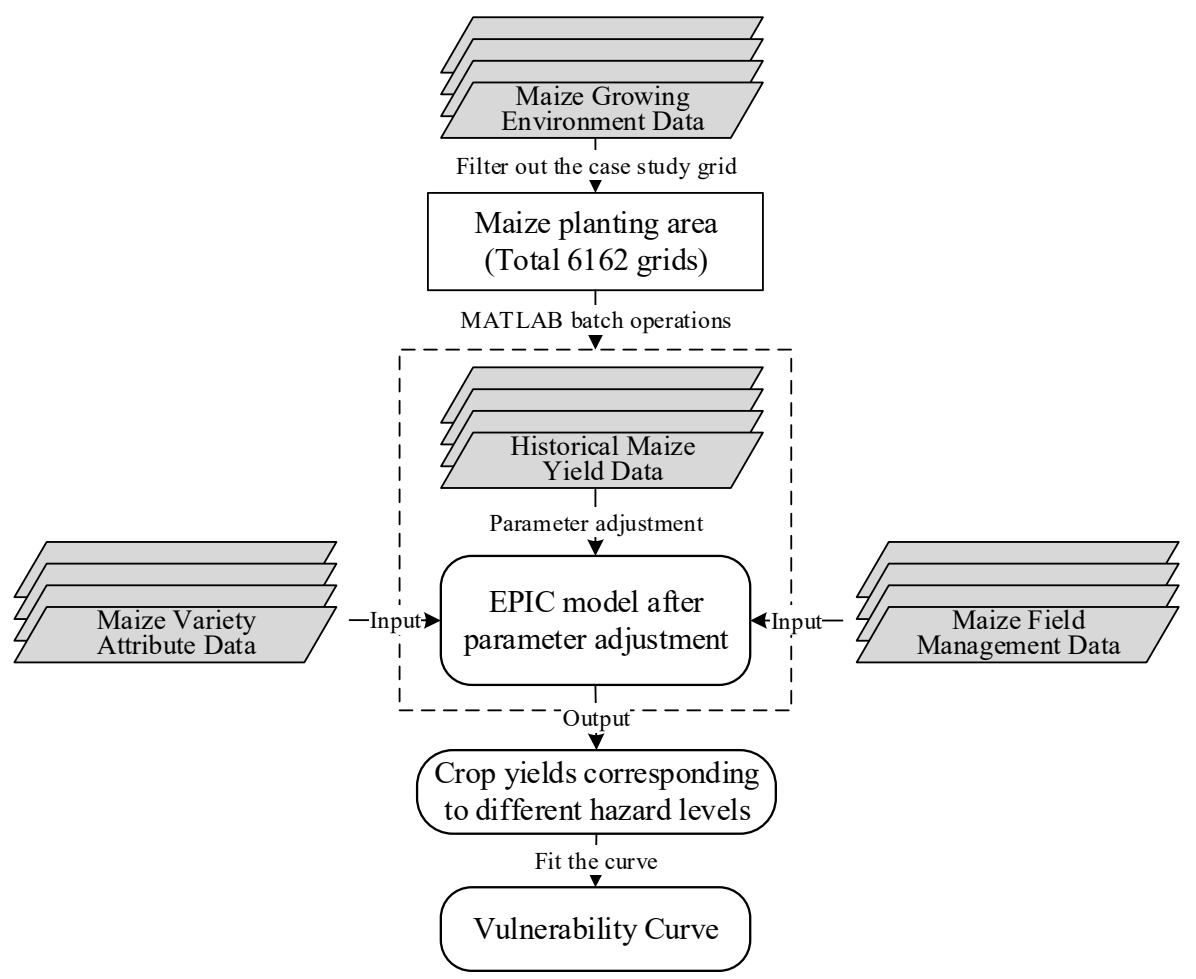

Figure 3. Process of EPIC model.

\section{Results}

\subsection{Accuracy of Epic Model Maize Yield Simulation}

In order to verify the accuracy of the simulated results calculated by the EPIC model, the simulated and actual maize yields for each year from 2000 to 2004 were plotted in scatter plots in this paper. The details are shown in Figure 4.

Pearson correlation analysis was conducted for simulated and actual average corn yields for each county from 2000 to 2004. The Pearson correlation coefficients between the average simulated and actual maize yields from 2000 to 2004 were $0.691,0.195,0.683,0.444$, and 0.592 ( $p$-value $<0.001)$, respectively. The simulated yield was $6.81 \mathrm{t} / \mathrm{ha}$ and the historical yield was $6.86 \mathrm{t} / \mathrm{ha}$, and the Pearson correlation coefficient was $0.495(p<0.001)$, indicating that the overall deviation in the simulated results was not significant. The over-origin fit was completed with the intercept-free model, and the fitted equation was $y=0.998 x$, with an RMSE of 0.949 , indicating a good calibration of the EPIC model in this paper. 

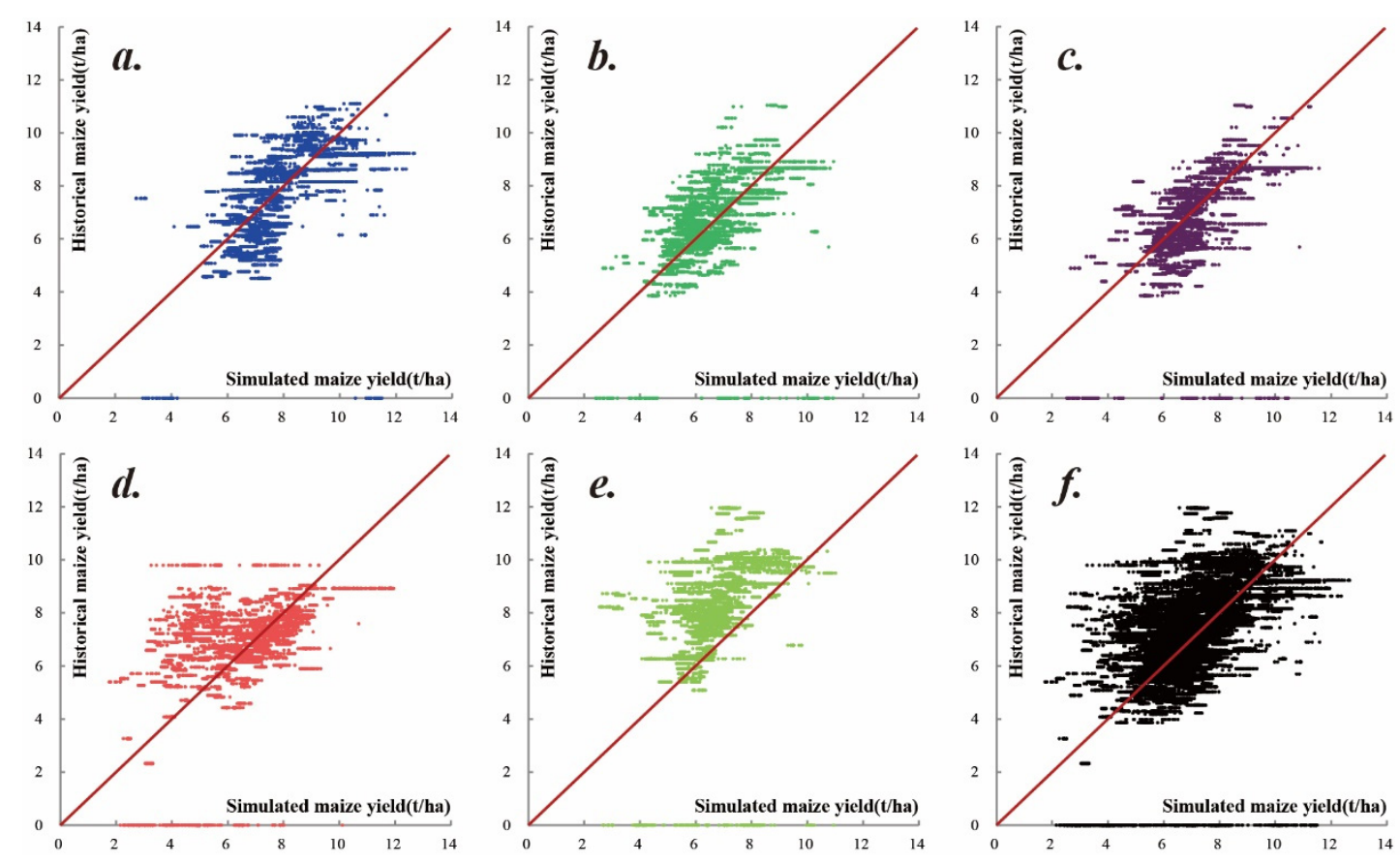

Figure 4. Correspondence between simulated and historical maize yield from years 2000 to 2004. Correspondence in 2000 (a); correspondence in 2001 (b); correspondence in 2002 (c); correspondence in 2003 (d); correspondence in 2004 (e); correspondence from 2000 to 2004 (f).

\section{2. "Precipitation Fluctuation and Maize Yield Stability" Vulnerability Curve}

Due to the spatial heterogeneity among different grids, it was not possible to plot the overall vulnerability curve for the study area. Therefore, the simulated yield data of 6162 grids in the study area were fitted to plot the "precipitation fluctuation and maize yield stability" vulnerability curve and to generate the corresponding functional equation. Based on the fitted coefficients and slopes, the curves were classified into three categories as follows. The vulnerability curves with a goodness of fit less than 0.6 were defined as Type III "precipitation fluctuation and maize yield stability" vulnerability curves. Type III vulnerability curves had slopes greater than zero or less than zero. These were considered to have an insignificant fit. Their scatter distribution was discrete and irregular. We spatialized Type I vulnerability curves and their slope distribution in Figure 5.

In these grids, the CV of simulated maize yield increased linearly with FLU, indicating that the yield stability deteriorated proportionately with increasing precipitation fluctuations. A total of 5713 grids resulted in Type I vulnerability curves, accounting for about $92.7 \%$ of the total maize planting grids. The grids with the lowest CV of maize yield under precipitation fluctuations were mostly located in New York, western Pennsylvania, southern New Jersey, and southern Virginia; the grids with a larger CV of maize yield under precipitation fluctuations were located in eastern Pennsylvania, Delaware, eastern Maryland, West Virginia, and northern Virginia; the grids with the largest CV of maize yield under precipitation fluctuations were located in Connecticut and central Maryland. This showed that maize yield stability in Connecticut and central Maryland was most strongly affected by precipitation fluctuations.

The CV of simulated maize yield decreased linearly with FLU, indicating that the yield stability improved proportionately with increasing precipitation fluctuations. A total of 17 grids were found to be Type II vulnerability curves, accounting for about $0.3 \%$ of the total maize planting grids. Type II vulnerability curves were clustered and distributed mainly near the southern state line in Virginia, and in discrete cases in northern New York. This indicated that there were very few cases where the CV decreased because of increasing precipitation fluctuations in the study area. We speculated that the irrigation 
water volume of the grids with Type II curves basically meets the needs of maize growth, and precipitation has almost no effect on it.

A total of 433 grids were found as Type III vulnerability curves, accounting for about $7.0 \%$ of the total maize planting grids. Type III grids were mainly located in the northern part of New York, Pennsylvania, the southeast corner of Pennsylvania, and the southern part of Virginia. Type III vulnerability curves implied that the yield stability in these grids were less dependent on the precipitation variation. We speculated that field management is the dominant factor affecting maize yield stability in these grids.
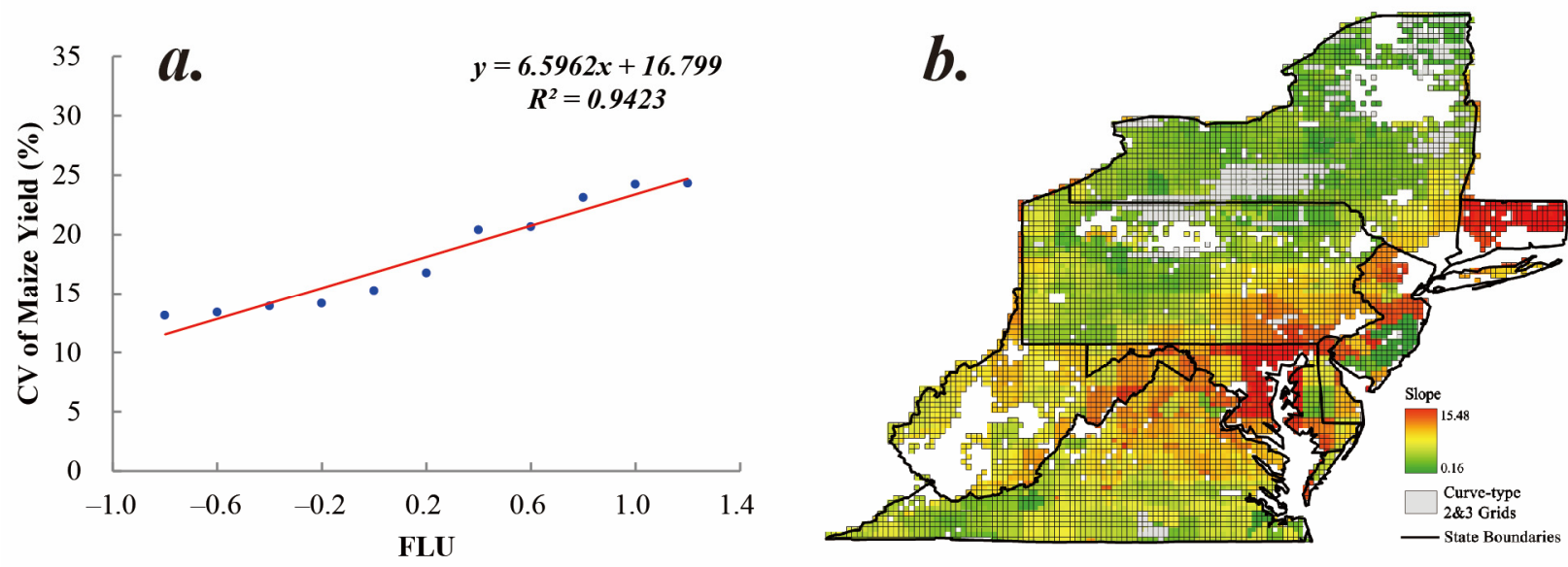

Figure 5. Type I vulnerability curve (a) and its slope distribution pattern (b).

\subsection{Distribution Pattern of CV of Maize Yield under Different Precipitation Fluctuation Scenarios}

The model simulation results showed that the CV of maize yield increased with FLU (Figure 6).

As seen in Figure 6, as FLU went from -0.8 to 1.2, the mean values of CV for maize yield in the study area were $0.128,0.131,0.137,0.145,0.155,0.169,0.183,0.197,0.208,0.219$, and 0.227 . Maize yield instability rose most significantly in Connecticut and Maryland. The CV of maize yield in Connecticut increased from below 0.15 at the FLU $=-0.8$ level to above 0.33 at the FLU $=1.2$ level. The CV of maize yield in Maryland increased from below 0.21 at the FLU $=-0.8$ level to above 0.39 at the FLU $=1.2$ level. The CV of maize yield change was least pronounced in New York, northern Pennsylvania, and central New Jersey, where the $C V$ of maize yield values remained constant at 0.03 to 0.2 . The $C V$ of maize yield in northeastern New York was lowest when the FLU was 0 and its CV increased regardless of FLU changes.

To analyze the statistical distribution of the CV of maize yield on each FLU level, the CV of all maize planting grids on each FLU level was plotted scattered in this paper, as in Figure 7.

The results showed that the maximum value of $\mathrm{CV}$ of maize yield increased with the FLU, and the maximum value of CV of maize yield increased from 0.28 to 0.43 . Besides, the minimum value of $\mathrm{CV}$ of maize yield remained around 0.03 and did not change much with the increase in FLU. It can also be seen from Figure 7 that when the FLU is less than 0, the scatter is more uniformly and densely distributed in the longitudinal direction; while, when the FLU is greater than 0, the scatter has obvious vacancies in the segment with $\mathrm{CV}$ values from 0.05 to 0.1 . This reflects that, excluding the very few CV stability areas (CV stay around 0 ), the CV of maize yield is positively correlated with FLU levels, and the magnitude of change varies from grid to grid. 

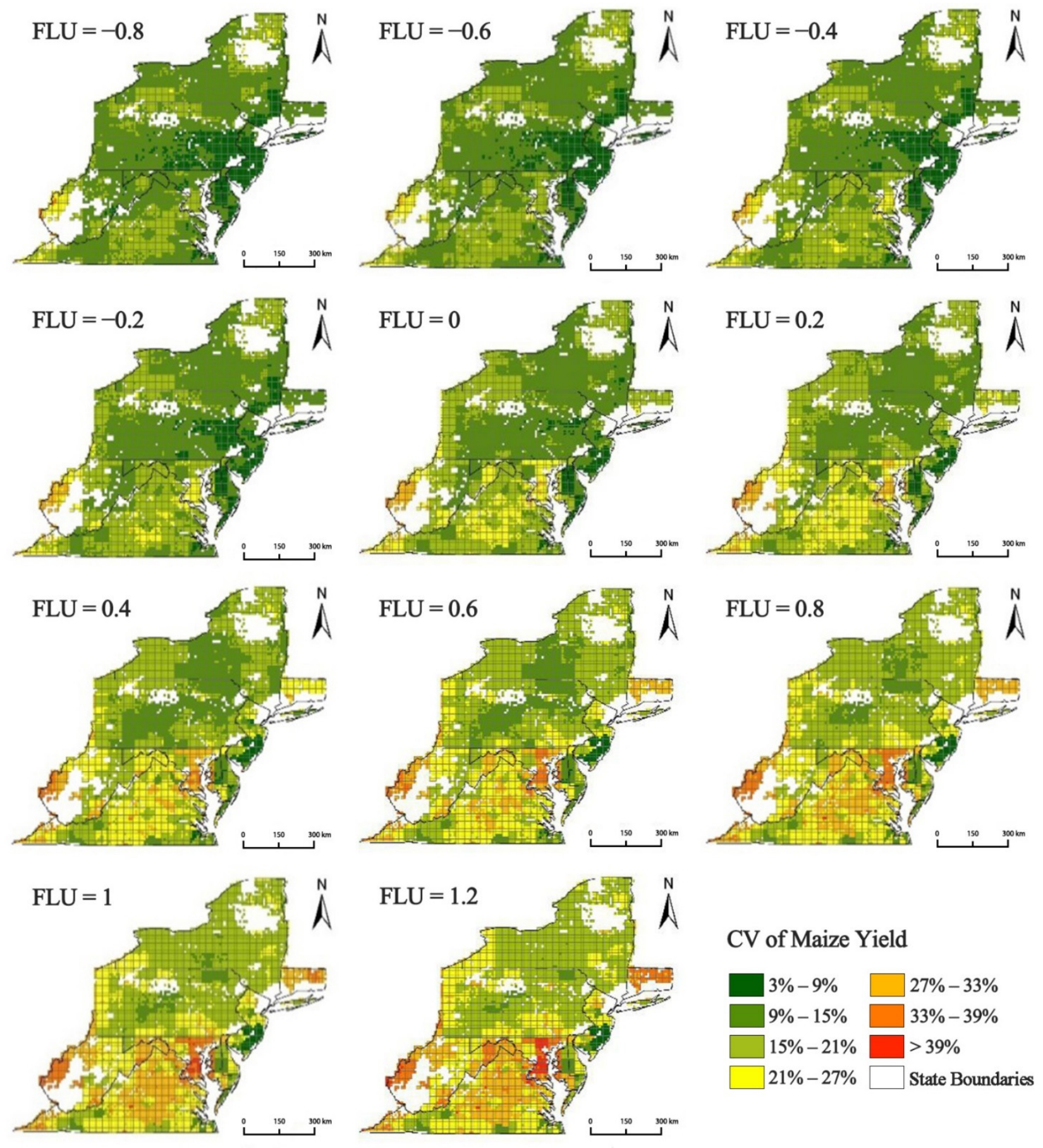

Figure 6. Distribution of CV of maize yield on each FLU level in the study area. 


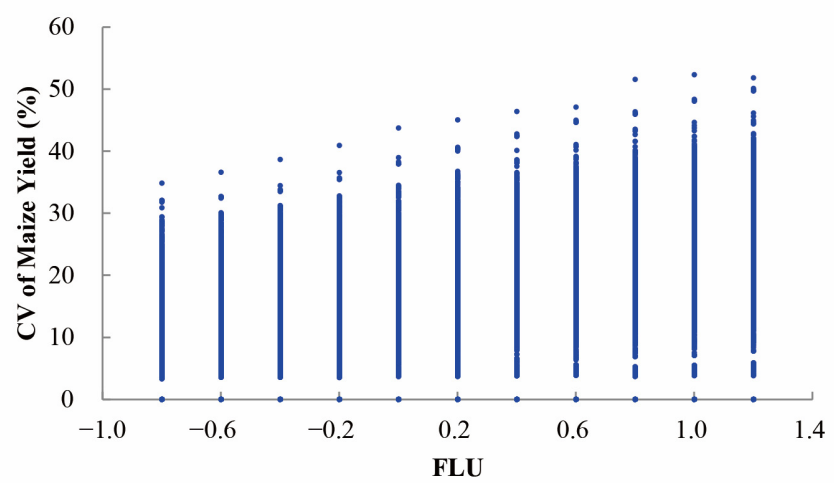

Figure 7. Statistical distribution of the CV of maize yield on each FLU level in the study area.

\section{Discussion}

\subsection{Vulnerability Curve Fitting Method Selection}

In this paper, pre-experiments were conducted to choose the vulnerability curve fitting method. The four curve types were exponential, logarithmic, linear, and power functions. The pre-experiment was divided into two steps; first, the scatter points of CV of maize yield under 11 precipitation fluctuation scenarios were fitted to obtain the coefficient of determination $\left(\mathrm{R}^{2}\right)$ of the curves on each grid; then, we calculated the mean value of $\mathrm{R} 2$ for all grids as the standard for comparing each type of curve. The four types of curve fits for one grid are plotted in Figure 8.
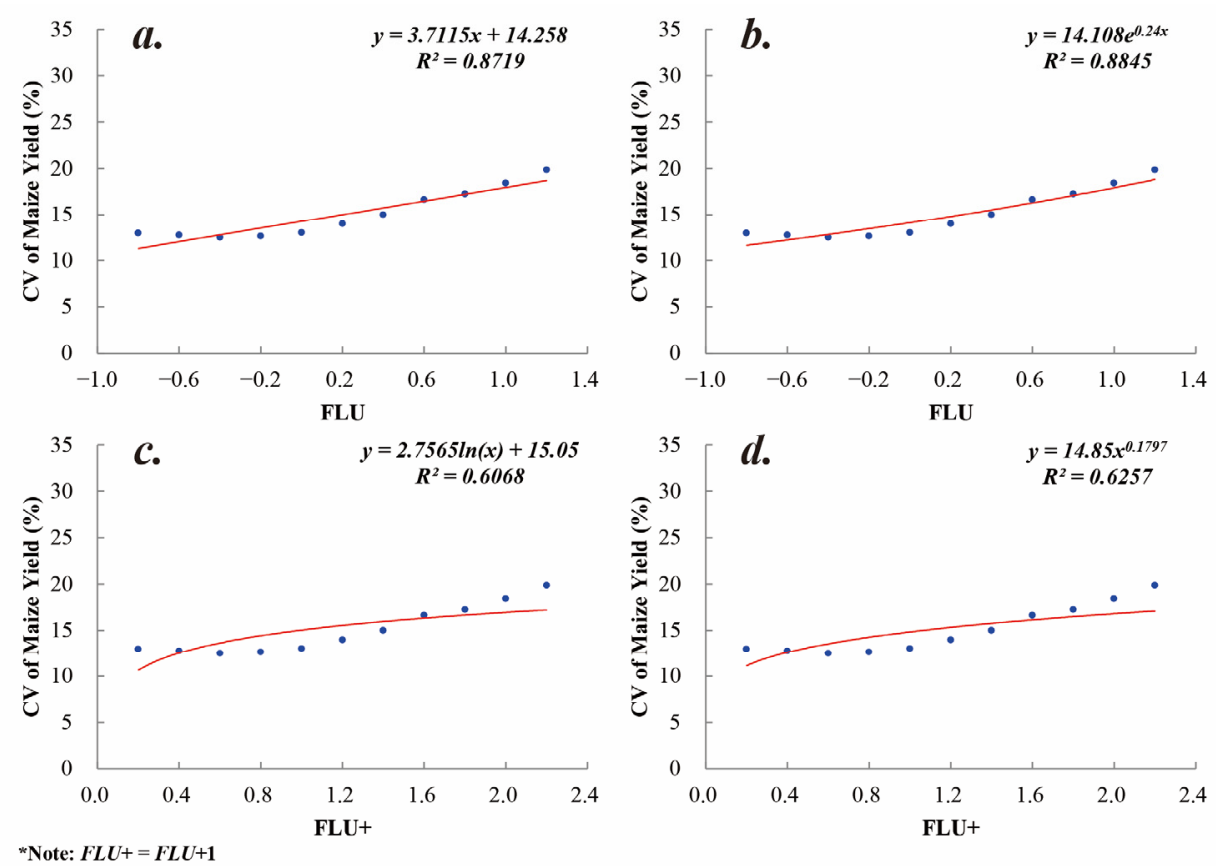

Figure 8. Fitting results of different functions to the vulnerability curve. Linear function (a); exponential function (b); logarithmic function (c); power function (d). Because of the value range of the independent variable, the independent variable is 'FLU+' (equal to 'FLU +1 ') in (c,d).

The mean values of $\mathrm{R}^{2}$ of the four types of curves were calculated as Table 2.

Among the four types of curves, the linear function and exponential function have similar $R^{2}$, both above 0.9 , with the exponential function having the highest $R^{2}$. The $R^{2}$ of the logarithmic function with the power function is low, at around 0.6. Given that the linear function is more intuitive in expression and the accuracy of the fitting results is high, the linear function is chosen for fitting in this paper. 
Table 2. Average of coefficient of determination $\left(R^{2}\right)$ of the curves.

\begin{tabular}{ccccc}
\hline & Linear Function & Exponential Function & Logarithmic Function & Power Function \\
\hline $\mathrm{R}^{2}$ & 0.9256 & 0.9287 & 0.6272 & 0.6359 \\
\hline
\end{tabular}

\subsection{Vulnerability Surface}

The disaster vulnerability curve only portrays the relationship between the hazard intensity and the crop yield loss rate [24,44,45]. Vulnerability curves are predicated on the assumption that there is only one input indicator (usually the hazard intensity). It does not fully describe the connotation of disaster vulnerability. If disaster vulnerability is considered as a functional relationship, the output is the crop yield loss, and the input factors include the environment (such as elevation, soil, and slope) and the hazard intensity (such as intensity and duration) [46]. Therefore, the vulnerability of different locations within the region varies, and the greater the spatial extent, the more pronounced the heterogeneity of vulnerability. Vulnerability surfaces are regional disaster vulnerability expressions that combine spatial location differences of the environments with vulnerability curves [5]. In order to compare vulnerability surfaces and vulnerability curves, the vulnerability surfaces of the $\mathrm{CV}$ of maize yield to precipitation fluctuations were plotted in this paper using elevation as the environment factor (Figure 9).

By comparing the two expressions, the vulnerability surface adds vulnerability at different elevations, thus reflecting the $\mathrm{CV}$ of maize yield under each precipitation fluctuation scenario at different elevations in the region, which makes the information of maize yield variability in the region more abundantly expressed. However, in risk assessment, vulnerability surfaces need to take into account more information about the environment, such as elevation and soil. However, a single vulnerability surface can only express a certain environment, which may require more work in practice. Hence, the study of vulnerability surfaces can be used as a future research direction for future vulnerability studies.
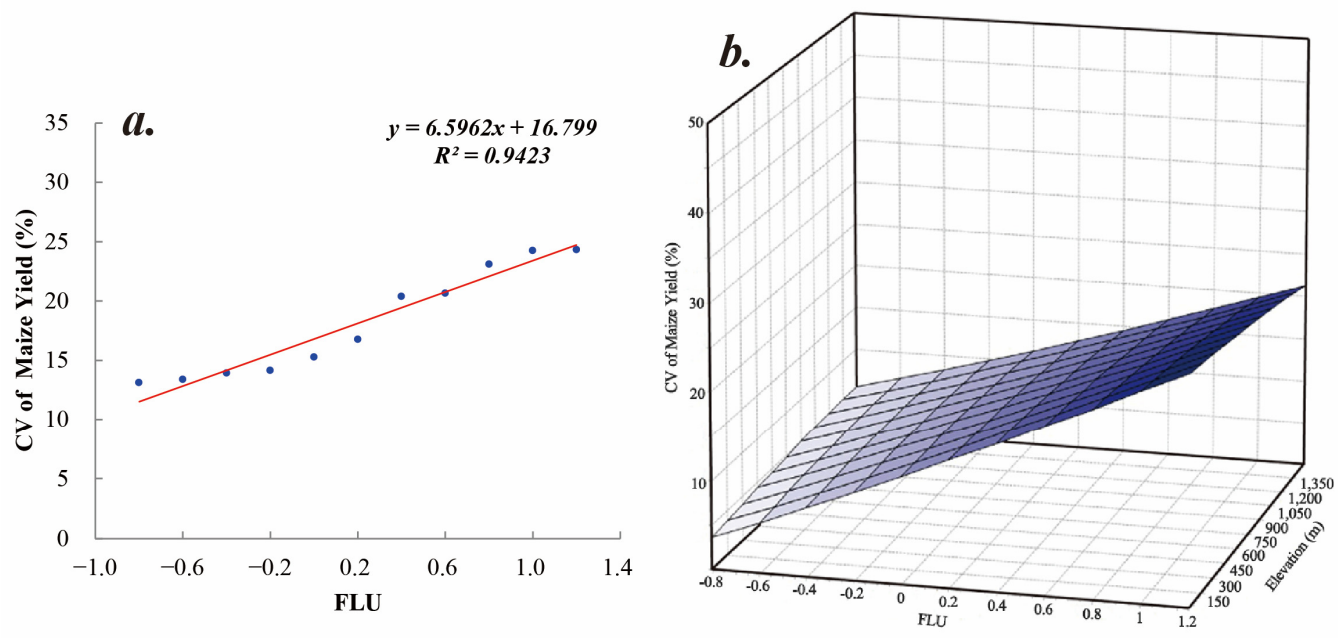

Figure 9. Comparison of vulnerability curve (a) and vulnerability surface (b).

\subsection{Limitations}

(1) Due to the availability of data, the climate data used in this paper were all extracted from the HadGEM2-ES climate model, instead of the observed meteorological data. However, the accuracy of the climate data generated by the HadGEM2 climate model has been proven by some studies. Collins et al. [47,48] compared the simulated results of each module of the HadGEM2 model with the observed data (such as aerosol and carbon fluxes), and proved the accuracy of each module of the model. Almagro et al. [49] compared historical climate simulations from the HadGEM2-ES model 
with observed precipitation data, and their results also proved that HadGEM2-ES is capable of representing long-term precipitation for the large areas.

(2) For the attribution of Type II and III curves, this paper only gives inferences, but there is no evidence to prove these inferences. Hence, the attribution of unexpected curve types is a direction for further study.

(3) This paper ignores the influence of agro-technological factors, such as sowing date, sowing depth, and variety of maize. Agro-technological factors largely determine the number of crops harvested under the conditions of a deficiency in abiotic factors. Hence, future research needs to take agro-technological factors into consideration.

\section{Conclusions}

In this study, based on the theory of hazard system risk assessment, the EPIC model was used to simulate maize yields, and its vulnerability curves were applied to study the changes in maize yield stability under 11 precipitation fluctuation scenarios in eight states in the northeastern United States and to analyze their spatial differences. The following conclusions were drawn.

(1) The "precipitation fluctuation and maize yield stability" vulnerability curves were well fitted by a unitary linear function using the FLU and the CV of maize yield of each grid as parameters in the study area (total 6162 grids). These 6162 curves can be classified into three categories (Type I, Type II, and Type III), accounting for $92.7 \%$, $0.3 \%$, and $7.0 \%$ of all curves, respectively. Type I has a slope greater than zero and a goodness of fit greater than 0.6 , which reflects the positive relationship between maize yield stability and precipitation fluctuations. In the grid of Type I, maize yield stability decreases with precipitation fluctuations. Type II has a slope less than zero and a goodness of fit greater than 0.6 , which reflects the inverse relationship between maize yield stability and precipitation fluctuations. Type III has a goodness of fit less than 0.6. In the grid of Type III, the correlation between maize yield stability and precipitation fluctuations is low, indicating that maize yield stability is more susceptible to the influence of other factors in this type.

(2) In the grids of Type I, the high-risk areas for maize cluster in Connecticut and central Maryland when precipitation fluctuations are greater than the historical values; when FLU $=1.2$, the CV of maize yield reaches $0.27-0.33$ for most of the grids in Connecticut and $0.29-0.45$ for the grids in central Maryland. The risk of maize yield stability is also higher in northern Virginia, northern New Jersey, and south-eastern Pennsylvania when precipitation fluctuations are greater than historical values, and the $C V$ of maize yield in these regions is greater than 0.21 when FLU $=1.2$. These regions should be priority areas for preventing the effects of precipitation fluctuations on maize.

(3) The study area was divided into eight regions to study the impact of precipitation fluctuation on maize yield. On a state scale, when precipitation fluctuations are greater than historical values, New Jersey and Connecticut have the least stable maize yields and should focus on strengthening maize yield risk prevention under precipitation fluctuations.

The above conclusions can provide a basis for mitigating the effects of maize yield variability under precipitation fluctuations. Besides, they provide a reference for the implementation of supplementary agricultural measures such as field irrigation to ensure high and stable maize yields.

Author Contributions: P.S. conducted the research, analyzed the data, and wrote the paper; S.L. processed the data and did extensive updating of the manuscript; J.W. conceived the research and provided project support; F.L. made suggestions to this paper. All authors have read and agreed to the published version of the manuscript.

Funding: This research was funded by the National Key Research and Development Program of China (Grant No.2016YFA0602402). 
Institutional Review Board Statement: Not applicable.

Informed Consent Statement: Not applicable.

Data Availability Statement: Data sharing not applicable.

Conflicts of Interest: The authors declare no conflict of interest.

\section{References}

1. Mbow, H.-O.P.; Reisinger, A.; Canadell, J.; O’Brien, P. Special Report on Climate Change, Desertification, Land Degradation, Sustainable Land Management, Food Security, and Greenhouse Gas Fluxes in Terrestrial Ecosystems (SR2); IPCC: Geneva, Switzerland, 2017.

2. Li, Y.; Ye, W.; Wang, M.; Yan, X. Climate change and drought: A risk assessment of crop-yield impacts. Clim. Res. 2009, 39, 31-46. [CrossRef]

3. Moriondo, M.; Giannakopoulos, C.; Bindi, M. Climate change impact assessment: The role of climate extremes in crop yield simulation. Clim. Chang. 2011, 104, 679-701. [CrossRef]

4. Challinor, A.J.; Watson, J.; Lobell, D.B.; Howden, S.; Smith, D.; Chhetri, N. A meta-analysis of crop yield under climate change and adaptation. Nat. Clim. Chang. 2014, 4, 287-291. [CrossRef]

5. Shi, P.-J. Theory on disaster science and disaster dynamics. J. Nat. Disasters 2002, 11, 1-9.

6. Shi, P.; Xu, W.; Ye, T.; Yang, S.; Liu, L.; Fang, W.; Liu, K.; Li, N.; Wang, M. World atlas of natural disaster risk. In World Atlas of Natural Disaster Risk; Springer: Berlin/Heidelberg, Germany, 2015; pp. 309-323.

7. Molua, E.L. Climate variability, vulnerability and effectiveness of farm-level adaptation options: The challenges and implications for food security in Southwestern Cameroon. Environ. Dev. Econ. 2002, 7, 529-545. [CrossRef]

8. Li, H.; Zhang, P.; Cheng, Y. Concepts and assessment methods of vulnerability. Prog. Geogr. 2008, 27, 18-25.

9. Shi, P.; Sun, S.; Wang, M.; Li, N.; Jin, Y.; Gu, X.; Yin, W. Climate change regionalization in China (1961-2010). Sci. China Earth Sci. 2014, 57, 2676-2689. [CrossRef]

10. Wilhelmi, O.V.; Wilhite, D.A. Assessing vulnerability to agricultural drought: A Nebraska case study. Nat. Hazards 2002, 25, 37-58. [CrossRef]

11. Bewket, W. Rainfall variability and crop production in Ethiopia: Case study in the Amhara region. In Proceedings of the 16th International Conference of Ethiopian Studies, Trondheim, Norway, 2-6 July 2007; pp. 823-836.

12. Simelton, E.; Fraser, E.D.; Termansen, M.; Benton, T.G.; Gosling, S.N.; South, A.; Arnell, N.W.; Challinor, A.J.; Dougill, A.J.; Forster, P.M. The socioeconomics of food crop production and climate change vulnerability: A global scale quantitative analysis of how grain crops are sensitive to drought. Food Secur. 2012, 4, 163-179. [CrossRef]

13. Farhangfar, S.; Bannayan, M.; Khazaei, H.R.; Baygi, M.M. Vulnerability assessment of wheat and maize production affected by drought and climate change. Int. J. Disaster Risk Reduct. 2015, 13, 37-51. [CrossRef]

14. Schilling, J.; Freier, K.P.; Hertig, E.; Scheffran, J. Climate change, vulnerability and adaptation in North Africa with focus on Morocco. Agric. Ecosyst. Environ. 2012, 156, 12-26. [CrossRef]

15. Adnan, S.; Ullah, K.; Gao, S.; Khosa, A.H.; Wang, Z. Shifting of agro-climatic zones, their drought vulnerability, and precipitation and temperature trends in Pakistan. Int. J. Climatol. 2017, 37, 529-543. [CrossRef]

16. Zhong, S.; Wang, C.; Yang, Y.; Huang, Q. Risk assessment of drought in Yun-Gui-Guang of China jointly using the Standardized Precipitation Index and vulnerability curves. Geomat. Nat. Hazards Risk 2018, 9, 892-918. [CrossRef]

17. Li, Y.; Guan, K.; Schnitkey, G.D.; DeLucia, E.; Peng, B. Excessive rainfall leads to maize yield loss of a comparable magnitude to extreme drought in the United States. Glob. Chang. Biol. 2019, 25, 2325-2337. [CrossRef] [PubMed]

18. Jayanthi, H.; Husak, G.J.; Funk, C.; Magadzire, T.; Adoum, A.; Verdin, J.P. A probabilistic approach to assess agricultural drought risk to maize in Southern Africa and millet in Western Sahel using satellite estimated rainfall. Int. J. Disaster Risk Reduct. 2014, 10, 490-502. [CrossRef]

19. Du, H.; Wu, Z.; Zong, S.; Meng, X.; Wang, L. Assessing the characteristics of extreme precipitation over northeast China using the multifractal detrended fluctuation analysis. J. Geophys. Res. Atmos. 2013, 118, 6165-6174. [CrossRef]

20. Kang, Y.; Khan, S.; Ma, X. Climate change impacts on crop yield, crop water productivity and food security-A review. Prog. Nat. Sci. 2009, 19, 1665-1674. [CrossRef]

21. Qiao, J.; Yu, D.; Liu, Y. Quantifying the impacts of climatic trend and fluctuation on crop yields in northern China. Environ. Monit. Assess. 2017, 189, 532. [CrossRef] [PubMed]

22. Lobell, D.B.; Burke, M.B. Why are agricultural impacts of climate change so uncertain? The importance of temperature relative to precipitation. Environ. Res. Lett. 2008, 3, 034007. [CrossRef]

23. Hamilton, T.W.; Ritten, J.P.; Bastian, C.T.; Derner, J.D.; Tanaka, J.A. Economic impacts of increasing seasonal precipitation variation on southeast Wyoming cow-calf enterprises. Rangel. Ecol. Manag. 2016, 69, 465-473. [CrossRef]

24. Zhou, Y.; Wang, J. A Review on Development of Vulnerability Curve of Natural Disaster. Adv. Earth Sci. 2012, $27,435-442$.

25. Doraiswamy, P.C.; Moulin, S.; Cook, P.W.; Stern, A. Crop yield assessment from remote sensing. Photogramm. Eng. Remote Sens. 2003, 69, 665-674. [CrossRef]

26. Prasad, A.K.; Chai, L.; Singh, R.P.; Kafatos, M. Crop yield estimation model for Iowa using remote sensing and surface parameters. Int. J. Appl. Earth Obs. Geoinf. 2006, 8, 26-33. [CrossRef] 
27. Rosenzweig, C.; Elliott, J.; Deryng, D.; Ruane, A.C.; Müller, C.; Arneth, A.; Boote, K.J.; Folberth, C.; Glotter, M.; Khabarov, N. Assessing agricultural risks of climate change in the 21st century in a global gridded crop model intercomparison. Proc. Natl. Acad. Sci. USA 2014, 111, 3268-3273. [CrossRef] [PubMed]

28. Tan, G.; Shibasaki, R. Global estimation of crop productivity and the impacts of global warming by GIS and EPIC integration. Ecol. Model. 2003, 168, 357-370. [CrossRef]

29. Adejuwon, J. Assessing the suitability of the EPIC crop model for use in the study of impacts of climate variability and climate change in West Africa. Singap. J. Trop. Geogr. 2005, 26, 44-60. [CrossRef]

30. Yue, Y.; Li, J.; Ye, X.; Wang, Z.; Zhu, A.-X.; Wang, J.-a. An EPIC model-based vulnerability assessment of wheat subject to drought. Nat. Hazards 2015, 78, 1629-1652. [CrossRef]

31. Mearns, L.; Mavromatis, T.; Tsvetsinskaya, E.; Hays, C.; Easterling, W. Comparative responses of EPIC and CERES crop models to high and low spatial resolution climate change scenarios. J. Geophys. Res. Atmos. 1999, 104, 6623-6646. [CrossRef]

32. Williams, J.; Jones, C.; Kiniry, J.; Spanel, D.A. The EPIC crop growth model. Trans. ASAE 1989, 32, 497-0511. [CrossRef]

33. Jia, H.; Wang, J.; Pan, D.; Cao, C. Maize drought disaster risk assessment based on EPIC model: A case study of maize region in northern China. Acta Geogr. Sin. 2011, 66, 643-652.

34. Wang, Z.; He, F.; Fang, W.; Liao, Y. Assessment of physical vulnerability to agricultural drought in China. Nat. Hazards 2013, 67, 645-657. [CrossRef]

35. Guo, H.; Zhang, X.; Lian, F.; Gao, Y.; Lin, D.; Wang, J.A. Drought risk assessment based on vulnerability surfaces: A case study of maize. Sustainability 2016, 8, 813. [CrossRef]

36. Meng, K.; Ekboir, J. Current and Future Trends in Maize Production and Trade; CIMMYT (International Maize and Wheat Improvement Center): Veracruz, Mexico, 2001.

37. Brush, S.B. The natural and human environment of the central Andes. Mt. Res. Dev. 1982, 2, 19-38. [CrossRef]

38. Ray, D.K.; Gerber, J.S.; MacDonald, G.K.; West, P.C. Climate variation explains a third of global crop yield variability. Nat. Commun. 2015, 6, 5989. [CrossRef] [PubMed]

39. Nuss, E.T.; Tanumihardjo, S.A. Maize: A paramount staple crop in the context of global nutrition. Compr. Rev. Food Sci. Food Saf. 2010, 9, 417-436. [CrossRef]

40. Meng, Q.; Chen, X.; Lobell, D.B.; Cui, Z.; Zhang, Y.; Yang, H.; Zhang, F. Growing sensitivity of maize to water scarcity under climate change. Sci. Rep. 2016, 6, 19605. [CrossRef] [PubMed]

41. Zhao, J.; Yang, X.; Sun, S. Constraints on maize yield and yield stability in the main cropping regions in China. Eur. J. Agron. 2018, 99, 106-115. [CrossRef]

42. Williams, J.R. The EPIC model. Comput. Models Watershed Hydrol; Water Resources Publications: Littleton, CO, USA, 1995; pp. 909-1000, ISBN 0918334918.

43. Fan, L.; Lu, C.; Chen, Z. A review of EPIC model and its applications. Prog. Geogr. 2012, 31, 584-592.

44. Papathoma-Koehle, M.; Keiler, M.; Totschnig, R.; Glade, T. Improvement of vulnerability curves using data from extreme events: Debris flow event in South Tyrol. Nat. Hazards 2012, 64, 2083-2105. [CrossRef]

45. Wu, S.; Jin, J.; Pan, T. Empirical seismic vulnerability curve for mortality: Case study of China. Nat. Hazards 2015, 77, 645-662. [CrossRef]

46. Kumpulainen, S. Vulnerability concepts in hazard and risk assessment. Spec. Pap.-Geol. Surv. Finl. 2006, 42, 65.

47. Collins, W.; Bellouin, N.; Doutriaux-Boucher, M.; Gedney, N.; Hinton, T.; Jones, C.; Liddicoat, S.; Martin, G.; O’Connor, F.; Rae, J. Evaluation of the HadGEM2 Model; Met Office Exeter: Devon, UK, 2008.

48. Collins, W.; Bellouin, N.; Doutriaux-Boucher, M.; Gedney, N.; Halloran, P.; Hinton, T.; Hughes, J.; Jones, C.; Joshi, M.; Liddicoat, S. Development and evaluation of an Earth-System model-HadGEM2. Geosci. Model Dev. 2011, 4, 1051-1075. [CrossRef]

49. Almagro, A.; Oliveira, P.T.S.; Rosolem, R.; Hagemann, S.; Nobre, C.A. Performance evaluation of Eta/HadGEM2-ES and Eta/MIROC5 precipitation simulations over Brazil. Atmos. Res. 2020, 244, 105053. [CrossRef] 